\title{
The Effects of Environmental Awareness and Consumption Value on Green Makeup Product Purchase Intentions
}

\author{
Genesis Guanghui Ma, Pei-Luen Patrick Rau*, Zhi Guo \\ Department of Industrial Engineering, Tsinghua University, Beijing, China \\ Email: *rpl@mail.tsinghua.edu.cn
}

How to cite this paper: Ma, G. G. H., Rau, P.-L. P., \& Guo, Z. (2018). The Effects of Environmental Awareness and Consumption Value on Green Makeup Product Purchase Intentions. Psychology, 9, 1898-1916. https://doi.org/10.4236/psych.2018.97110

Received: June 28, 2018

Accepted: July 28, 2018

Published: July 31, 2018

Copyright (c) 2018 by authors and Scientific Research Publishing Inc. This work is licensed under the Creative Commons Attribution International License (CC BY 4.0).

http://creativecommons.org/licenses/by/4.0/

\section{(c) (i) Open Access}

\begin{abstract}
Green marketing in the cosmetics industry is emerging and gathering importance, and it dates back to the wave of environmental concern. Therefore, the study aims to explore the effects of environmental awareness and consumption values on the green makeup purchase intention, and examine whether there is a cultural difference. 124 participants answered the questionnaire with all variables. The structural equation model built on the survey data suggested that: 1) environmental attitude and perceived consumer effectiveness in environmental awareness, and epistemic and functional consumption values had a positive relationship with green makeup purchase intention, but social consumption value had a negative relationship with green makeup purchase intention; 2) the model got from international students was very close to what got from whole data pool, but the dimensions of environmental awareness and social value had no relationship with green makeup purchase intention in Chinese student sample. Findings provide implications for promoting green marketing in cosmetics market.
\end{abstract}

\section{Keywords}

Environment Awareness, Consumption Values, Green Consumption, Eco-Friendly Makeup, Cosmetics

\section{Introduction}

Green marketing in the cosmetics industry is emerging and gathering importance, as the public becomes more aware of the health and environmental dangers associated with the cosmetic industry. Its history can be traced back to the wave of environmental concern in the 1970s (Henion, 1976). From face scrubs to 
lipstick, cosmetics laced with dangerous ingredients can cause pollution, kill plants and animals, and impact consumer's health by rinsing down drains into lakes, oceans or rivers. But the serious discussion on sustainability in marketing and its physical implications wasn't raised until 1990s (Vining \& Ebreo, 1990). Many countries began to advocate green consumption in order to have the consumer pay much more attention to their living conditions for future. As a result, the consideration of eco-friendliness of goods played a critical role among societies (Philippe, Didillon, \& Gilbert, 2012). However, how to promote the green makeup purchase intention is still not fully studied.

Due to that women on average make purchase and use more cosmetics than men, we would like to focus on female consumers to find significant results. Because green products are the goods or services that been reduced, minimize or has absolutely no harm to the environment. Thereby the purpose of the present study is to examine the effects of environmental awareness and consumption values on green makeup purchase intention of females. Furthermore, China as one of the world's largest economies, has much potential in cosmetics market. Therefore, the present study also compared the difference of these effects in Chinese sample and international person sample.

\subsection{Environmental Awareness and Green Consumption}

Environmental awareness is having knowledge on the conditions of someone or something's surrounding. Angelovska, Sotiroska, \& Angelovska (2012) addressed in her study that it is very important to enhance the environmental awareness to societies in order to raise pro-environmental concern among consumers and females have higher level of consciousness of environment if regardless of their income level. How to live under an environmental friendly lifestyle is the main concern of environmental awareness studies. Environmental awareness includes environmental attitude, environmental concerns, environmental knowledge and perceived consumer effectiveness.

Environmental Attitude has been found as the direct influential indicator on responsible environmental behavior (Roberts \& Bacon, 1997). Kim \& Choi (2005) found out that the environmental attitude could be seen as the general concerning level of environmental issues in their study.

Environmental concerns have often been considered as one of the important factors to measure consumer's environmental awareness based on their environmental responsibility (Kinnear, Taylor, \& Ahmed, 1974). Lepisto (1974) found out that great environmental concern level of consumers represented the interest level of environmental surroundings to them. For example, if the consumers be more aware of the facts of green products, such as by switching the products could save thousands of animal lives per year when, thus they would be more likely to understand the harms that they face by not choosing the green products.

Scholars also found out that there is a close relationship between environ- 
mental knowledge and green consumption behavior (Angelovska et al., 2012), and the knowledge closely links with likelihood to participant pro-environmental activities (Samdahl \& Robertson, 1989; Van Liere \& Dunlap, 1981). Vining and Ebreo (1990) also found out that most of the green behavioral studies discussed the positive relationship between environmental knowledge and green behavior.

Perceived consumer effectiveness is the measurement to judge the subject in the impact of individual consumers on environmental resource problems. In Kinnear et al. (1974) study, they found out that individuals would raise their concerns toward environment once they found out they can actually make differences. As a result, they would increase tendency to show environment related attitudes and behavior (Henion, 1976).

\subsection{Consumption Values and Green Behavior}

Another important perspective to understand the consumption behavior would be consumption value (Hellier, Geursen, Carr, \& Rickard, 2003). Sheth, Newman, \& Gross (1991) stated that there are five different categories of consumption values, emotional, social, epistemic, conditional, and functional values. Emotional value often associated with aesthetic alternatives, which based on the evaluation of a product by how consumers feel toward it. Social Value is related with association with perceived social consequences, which also be seen as the environmental norm in green market. It is about how individual views his/her own image by comparing his/her decision to the others in the situation. Epistemic value is about to fulfil the curiosity of consumers to certain products or knowledge. Functional value is related to certain choice to satisfy physical purposes from the consumers, which is to be useful to the consumers for a certain purpose, such as price. Conditional value would affect the consumer's decision in the short run. Therefore, we didn't consider this short-term impact value into our model for decision behavior.

In China, the consumption value within their culture is unique, compared to the western countries. The nations which are developed from Confucianism such as China, Korea, and Japan have a very strong belief to conform to the majority of the society, and they worry more about whether they would lose "face" in front of the others (Tsai, Chim, \& Sims, 2015).

Base on the behavior model (Montano \& Kasprzyk, 2015) and the literature reviews, we proposed environmental awareness and consumption values would simultaneously influence the person's green makeup purchase intention, and the models would be different between Chinese and international samples.

\section{Methods}

\subsection{Participants}

133 female university students were recruited by a popular online survey platform named Wenjuanxing in China (https://www.wjx.cn/). Both Chinese and English versions of the survey were sent out through the survey platform in or- 
der to make both Chinese and international female students able to participant the survey. Two criteria were used to screen the participants who responded arbitrarily. Firstly, age must be over 16 years old. The same score should be rated on less than $90 \%$ of the items. Secondly, correlations with other participants should all be less than 0.95 (meaning not copying other's answer), but no less than mean minus three S.D. Ultimately, we obtained 124 valid responses, including Chinese students (68\%) and international students (32\%). Out of all the international students, $53 \%$ were Asian, and $18 \%$ were Caucasian. The age range of the valid sample was $17-29$ years $(22.6 \pm 2.38)$.

The sample characteristic was displayed in Table 1. Out of the valid sample, most of the respondents had got master degree (55\%). As to income level, 67\% are more than 5000 RMB. $63 \%$ of the participants had online shopping experience about makeup products and $43 \%$ have willingness to pay less than 30 RMB extra on green products. $75 \%$ of the participants got the knowledge of makeup from internet, family and friends.

\subsection{Materials}

All the variables were measured in a questionnaire. A total of 110 items has been asked, including questions for each variable as well as basic general information of consumers (see Appendix). The first part is demographic information of consumer, the second is the environmental awareness and consumption values, and the third one is the purchase intention.

\subsubsection{Environmental Awareness and Consumption Values}

The items of environmental awareness and consumption values were revised based on previous related literatures (Afroz, Masud, Akhtar, Islam, \& Duasa, 2015; Martinho, Pires, Portela, \& Fonseca, 2015). Each variable includes four dimensions and each dimension includes four items.

The items of environmental awareness: e.g. "The balance of nature is very delicate and easily upset." measured environmental attitude, "Because fertilizer can promote the production of crops, the more fertilizer the better." measured environmental knowledge, "I can protect the environment by buying products that are friendly to the environment." measured environmental concern/norm, and "I would pay one yuan more per month to support greater control of environment." measured perceived consumer effectiveness.

As to the items of consumption values, they were answered under the scenario of lipstick (lipstick is widely known and used among female university students). E.g. "Buying the following green products would make me feel like I am a better person." measured emotional value, "Buying the following green products would show my sympathy and my caring." measured social value, "I would acquire a great deal of information about what are the differences that make green products so special." measured epistemic value, and "I think the following green products are reasonably priced." measured functional value. In addition, in order to understand whether the impact of consumption values on lipsticks is 
Table 1. The characteristics of the valid sample.

\begin{tabular}{|c|c|c|}
\hline Demographic & & Percentage \\
\hline \multirow{3}{*}{ Nationality } & Chinese & 68 \\
\hline & International & 32 \\
\hline & Bachelor & 35 \\
\hline \multirow[t]{2}{*}{ Education Level } & Master & 55 \\
\hline & Doctor & 10 \\
\hline \multirow{3}{*}{ Income Level (RMB) } & $<5000$ & 33 \\
\hline & $>5000$ & 67 \\
\hline & Online & 63 \\
\hline \multirow{5}{*}{ Shopping Habit (makeup) } & Department Store & 60 \\
\hline & Open-shelf & 30 \\
\hline & Some Small shops & 15 \\
\hline & $<30$ & 43 \\
\hline & $31-60$ & 19 \\
\hline \multirow[t]{5}{*}{ Willingness to Pay Extra on Green Products (RMB) } & $61-100$ & 12 \\
\hline & $101-200$ & 13 \\
\hline & $>200$ & 13 \\
\hline & Internet & 75 \\
\hline & Family/Friends & 75 \\
\hline \multirow[t]{3}{*}{ Knowledge of Makeup Learned from } & Sales/Store & 25 \\
\hline & Movie & 24 \\
\hline & Magazines & 13 \\
\hline
\end{tabular}

consistent with the effects of other products on environmental friendly aspect, clothes was added as its comparable object. Lipsticks and clothes share similar traits in terms of consumer's green purchasing decision. Firstly, both are durable consumer items and are touched directly to our skin. Secondly, both are sensitive to fashion trends and should be repurchased over a certain time period. A sustainable and continuous shopping decision need to be made for both of them. Thirdly, both can be sensitive to chemical or manmade materials for consumers, and face the problem of packaging waste. Lastly, animal harm involved in both makeup and clothes, including animal testing and animal killing for fur.

Items were assessed by the seven-point Likert scale $(1=$ Definitely Disagree means you are 100\% disagreed with the statement. $2=$ Quite Disagree means you are $80 \%$ disagree with the statement. $3=$ Slightly Disagree means you are $60 \%$ disagree with the statement. $4=$ Not Sure means you are $50 \%$ disagreed and $50 \%$ agreed with the statement. $5=$ Slightly agree means you are $60 \%$ agreed with the statement. $6=$ Quite agree mean you are $80 \%$ agree with the statement. $7=$ Definitely agree means you are $100 \%$ agreed with the statement). 


\subsubsection{Green Makeup/Clothes Purchase Intention}

Purchase intention questionnaire contains 7 items based on previous studies (Afroz et al., 2015), e.g. "I recommend green makeup/clothes that I consumed to my relatives and friends", "I will buy green makeup to guarantee my health" etc. It was also measured by the same seven-rating Likert scale.

\subsection{Data Analysis}

Structural equation modelling has been used to analyze the data, which is common in social research, especially the partial least square structural equation modelling (PLS-SEM) with bootstrapping procedure. Traditional criteria such as Cronbach Alpha (Numally, 1978), Composite Reliability (Werts, Lim, \& Joreskog, 1974), and Average Variance Extracted (Fornell \& Larcker, 1981) were used to assess the model fitness. Each dimension of independent variables need to consider three different statistical values after CFA, respectively Cronbach's alpha ( $>0.6)$, composite reliability $(>0.7)$ and average variance extraction values $(>0.5$, since the data size lie between $120-150)$.

The abbreviations of variables were used in SEM as followings (see Table 2): Environmental Attitude (EA), Environmental Knowledge (EK), Environmental Concern/Norm (EC), Perceived Consumer Effectiveness (PCE), Emotional Value for makeup/clothes (EMLP/EMCL), Social Value for makeup/clothes (SCLP/ SCCL), Epistemic Value for makeup/clothes (EPLP/EPCL), Functional Value for makeup/clothes (FCLP/FCCL), Animal Testing (ATA), Brand Sensitivity (BRA), Chemical Ingredients (CHA), Fashion Trend (FTA), Media Impact (MEA), Quality Concern (QUA), Wastes and Recycling (RWA), Social Pressure (SPA), The Intention of Green Makeup Purchasing Decision (DC).

\section{Result and Analysis}

After PLS-SEM algorithm, the original results of green makeup purchase intention were seen in Table 3 and Figure 1. In original model, Cronbach's alpha ( $>0.6)$, composite reliability $(>0.7)$ and average variance extraction values $(>0.5)$ in Table 3 suggested consumption values overall were more reliable and valid than environmental awareness and external variables, like impact of branding, media, function and overall environmental sectors were not enough reliable and valid to predict the intention of green makeup purchase. The factor loadings of items about environmental attitude, environmental knowledge, environmental concern and external variables in Figure 1 varied significantly within the dimension. It suggests the variances of loadings within environmental attitude, environmental knowledge, environmental concern and external variables were larger than those within each dimension of consumption values. For example, the first item's factor loading on environmental concern was 0.218 , while the second item's loading was 0.846 . Therefore, the loadings in Figure 1 supported the finding got based on Table 3. We originally assume that external variables such as branding would and chemical ingredients would have significant impact on consumers' purchase decision (Bearden \& Etzel, 1982). But the results (see 
Table 2. The abbreviation of variables in SEM analysis.

\begin{tabular}{|c|c|c|}
\hline Variables & Dimensions & Abbreviations \\
\hline \multirow{4}{*}{ Environmental Awareness } & Environmental Attitude & EA \\
\hline & Environmental Knowledge & EK \\
\hline & Environmental Concern & $\mathrm{EC}$ \\
\hline & Perceived Consumer Effectiveness & PCE \\
\hline \multirow{4}{*}{ Consumption Values } & Emotional Value & EMLP(lipstick)/EMCL(clothes) \\
\hline & Social Value & SCLP/SCCL \\
\hline & Epistemic Value & EPLP/EPCL \\
\hline & Functional Value & FCLP/FCCL \\
\hline \multirow{7}{*}{ External Variables } & Animal Testing & ATA \\
\hline & Brand Sensitivity & BRA \\
\hline & Chemical Ingredients & $\mathrm{CHA}$ \\
\hline & Fashion Trend & FTA \\
\hline & Media Impact & MEA \\
\hline & Quality Concern & QUA \\
\hline & Wastes and Recycling & RWA \\
\hline & Social Pressure & SPA \\
\hline $\begin{array}{l}\text { Green Makeup Purchasing } \\
\text { Intention }\end{array}$ & $\begin{array}{c}\text { The Intention of Green Makeup } \\
\text { Purchasing Decision }\end{array}$ & DC \\
\hline
\end{tabular}

Table 3. The Cronbach's alpha, composite reliability and average variance extraction of independent variables in original model of green makeup purchase intention.

\begin{tabular}{cccc}
\hline & Crobach's Alpha & Composite Reliability & Average Variance Extracted \\
\hline EA & 0.287 & 0.506 & 0.392 \\
EK & 0.590 & 0.557 & 0.289 \\
EC & 0.294 & 0.316 & 0.304 \\
PCE & 0.601 & 0.768 & 0.456 \\
EMLP & 0.822 & 0.880 & 0.649 \\
SCLP & 0.702 & 0.815 & 0.527 \\
EPLP & 0.733 & 0.825 & 0.542 \\
FCLP & 0.756 & 0.843 & 0.575 \\
External Variables & 0.585 & 0.391 & 0.148
\end{tabular}

Table 3) did not support the hypothesis. The reason might be that the original study was done back in 1980's, the new generations are less sensitive to branding as how it is today. Another reason might be that due to the fact our participants are still students, therefore impacted by their income level and social experience, their needs or purchasing power influenced or limited their final decisions on famous branding products. As for chemical ingredients, we thought consumers 


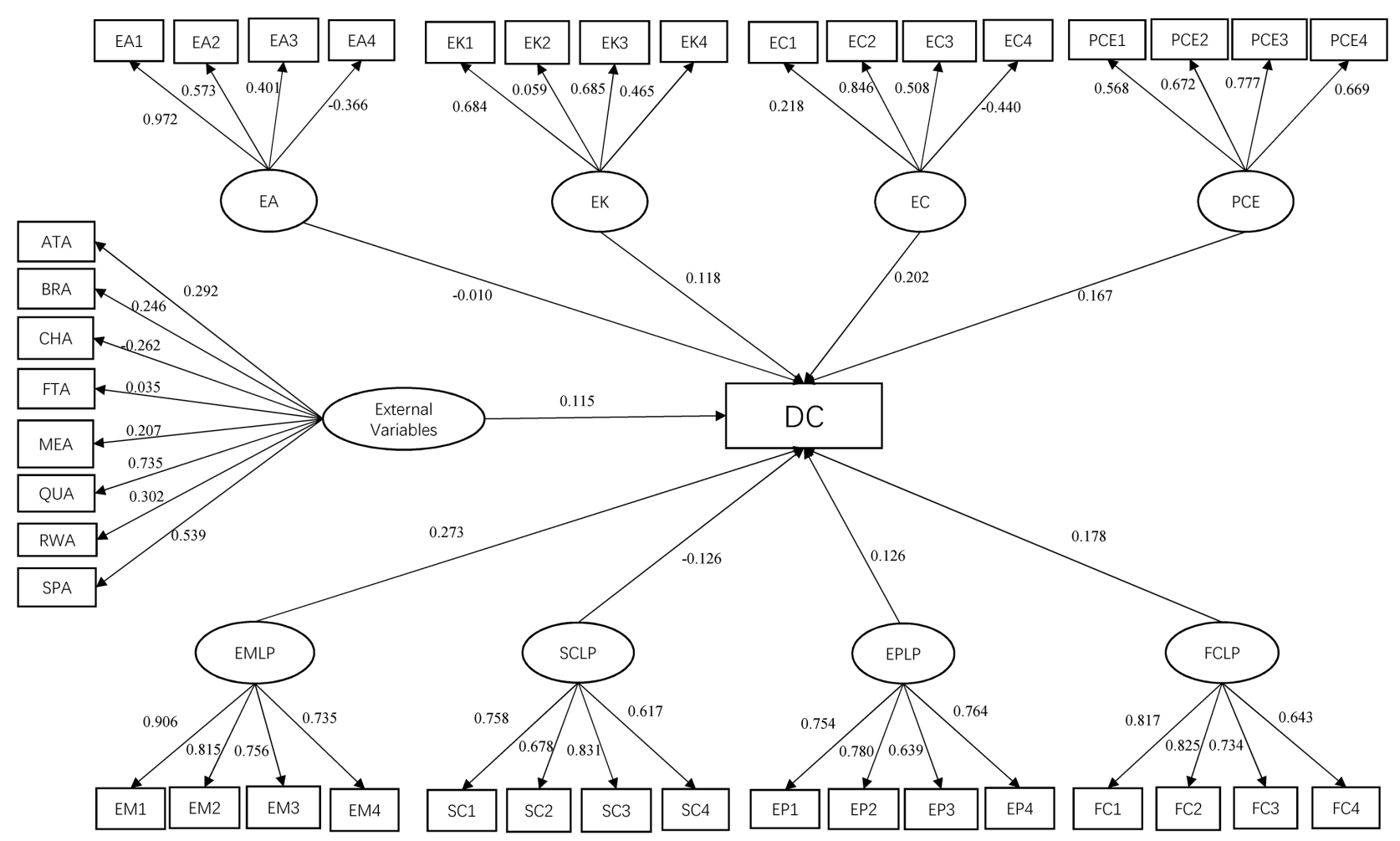

Figure 1. The original model of environmental awareness, consumption values and green makeup purchase intention.

would have high level of concerns when mentioning what they would put on their skin, since it can be toxic and cause damage to their health (Al-Saleh \& Al-Enazi, 2011). The results (see Table 3) also did not support the hypothesis. One of the reasons is that many consumers in market do not understand the risk behind makeup products and easily forget about to check the ingredients list on package while shopping, which is very similar to the case for food shopping that many people do not pay close attention to what they eat even though it is available on those packages. The other reason is that the ingredients shown on package are hardly to understand what they really are or do to our body. All the names are being listed with formal chemical terms, without solid background of chemical knowledge it is very hard for consumer to understand what they really are just by looking at their term names.

Instead, quality and social pressure are more important for purchase decision in our sample pool. On average, our participants believe that higher price equals higher quality rather than brand, but if they know two products have same quality then they would prefer to lower priced product. This also refers back to why in our case, branding is not as significant as we thought in the first place for makeup purchase decision. But in real life case, we do not have the fully understanding or information to measure certain products' quality, therefore price is still being a major player for purchase decision. The other variable which is very interestingly shown is social pressure. According to our loading value, social pressure has the highest rate among all external variables. It means that participants act more towards to what their surroundings show or tell them to do so. 
They are act as social follower in this case. More interesting enough, if we look at the average rate on results, participants answered that they will not be influenced by surroundings and they make their own decisions. On the other hand, if we look at social value under consumption values, it has a negative impact on green purchasing decision. Participants are being asked whether they think they feel better or smart if they purchase a green product compared to the others who do not. On average, participants agreed that would help them to think they are better than others if to do so but instead from our findings regardless of what they think as individuals they would still follow others in the market as a consumer.

According to the model fit criteria, the original model was finally revised as the one shown in Figure 2. Table 4 shows that all the dimensions of the independent variables in the model meet the criteria of Cronbach's alpha, composite reliability and average variance extraction. Overall, we deleted external variables, environmental concern/norm, and environmental knowledge from our previous model based on our calculation result. It tells us that those variables are not reliable enough to predict green consumption behavior overall from our sample pool, two out of four environmental awareness variables cannot be proved that are have significant correlation to our hypotheses. Some of the possible explanations are that the questions under environmental knowledge variables are not directly linked to makeup industry, so the connection to green makeup purchase decision is relatively weak. This also reflects back to the fact that participants did not care too much about chemical ingredients or its damage in their decisions even though they might know there is a risk, but decided to ignore or did not consider. Participants have relatively high level of environmental concern with an average of 5.4 out of 7 to favor pro-environmental statements, but when they make a purchase, they tend to easily forget about their social responsibility. When they do not face the problem directly, it is hard for them to consider the impact behind their un-green purchase decisions.

Table 4. The Cronbach's alpha, composite reliability and average variance extraction of independent variables in final model of green makeup purchase intention.

\begin{tabular}{cccc}
\hline & Crobach's Alpha & Composite Reliability & Average Variance Extracted \\
\hline EA & 0.641 & 0.769 & 0.644 \\
PCE & 0.601 & 0.779 & 0.543 \\
EMLP & 0.822 & 0.880 & 0.649 \\
SCLP & 0.702 & 0.851 & 0.527 \\
EPLP & 0.733 & 0.825 & 0.542 \\
FCLP & 0.756 & 0.843 & 0.575 \\
\hline
\end{tabular}

Note: Environmental Attitude (EA), Environmental Knowledge (EK), Environmental Concern/Norm (EC), Perceived Consumer Effectiveness (PCE), Emotional Value for makeup/clothes (EMLP/EMCL), Social Value for makeup/clothes (SCLP/SCCL), Epistemic Value for makeup/cloths (EPLP/EPCL), Functional Value for makeup/clothes (FCLP/FCCL), the Intention of Green Makeup Purchasing Decision (DC). 


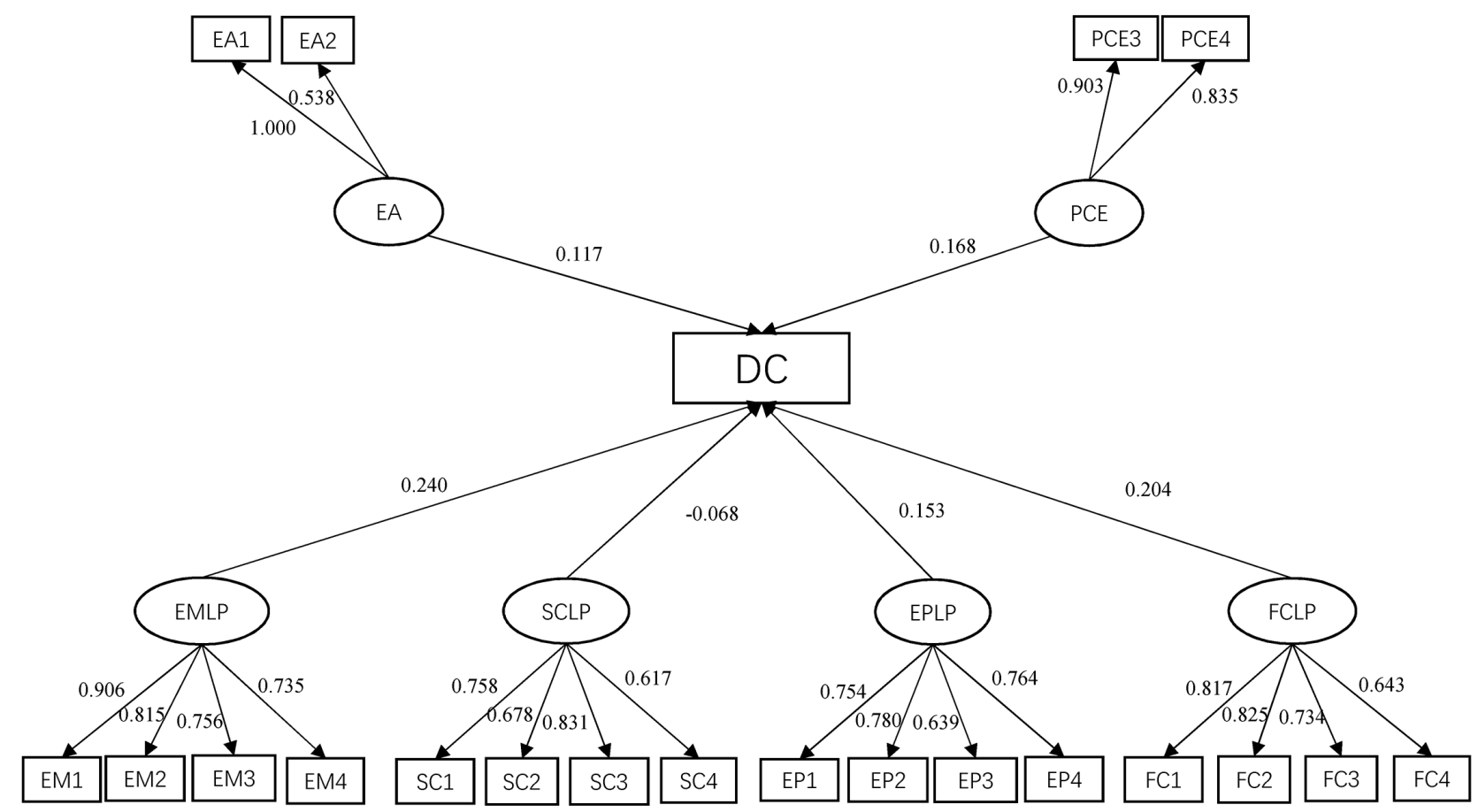

Figure 2. The relationships of environmental awareness, consumption values and green makeup purchase intention.

A couple of times of bootstrap were further conducted to look at the overall path coefficients and test out whether the p-values are less than 0.05 for its significance. The results shown that only emotional value has a p-value less than 0.05 , which indicated that we cannot be certain that there is a positive relationship between emotional value and green makeup purchase decision from all the consumption values aspect. The possible explanation is that it is hard for us to predict emotional decision because it is very unstable especially for behavior studies (Salovey \& Grewal, 2005). The other thing we would like to point out that even though under p-value social value is accepted but its actual coefficient is negative, in which case it means that even though the participants agree that they should make their decision individually but they do not do what they think when they are under social pressures. Whether what we do is right or not, we follow the steps of the majorities (Garicano, Palacios-Huerta, \& Prendergast, 2005). Cheah \& Phau (2011) found out that the individual who sees him/herself as a team player would willing to give up on personal feelings in order to match up with others towards the social goals, which would also imply on the prediction of responsible environmental behavior.

As we mentioned previously, we decided to compare participants' purchase decision on two different objects, makeup and clothes to be certain about what are the true key variables to impact on their green purchase decisions. The final model of green clothes purchase intention was seen in Table 5 and Figure 3. It is a very different model compared to object lipstick model. We did not have social value nor perceived consumer effectiveness variables anymore, in addition, the indicators of EM4, EP1, FC3 and FC4 were not being considered either. 
Table 5. The Cronbach's alpha, composite reliability and average variance extraction of independent variables in final model of green clothes purchase intention.

\begin{tabular}{cccc}
\hline & Crobach's Alpha & Composite Reliability & Average Variance Extracted \\
\hline EA & 0.679 & 0.769 & 0.644 \\
EMCL & 0.767 & 0.861 & 0.675 \\
EPCL & 0.746 & 0.847 & 0.651 \\
FCCL & 0.676 & 0.860 & 0.755 \\
\hline
\end{tabular}

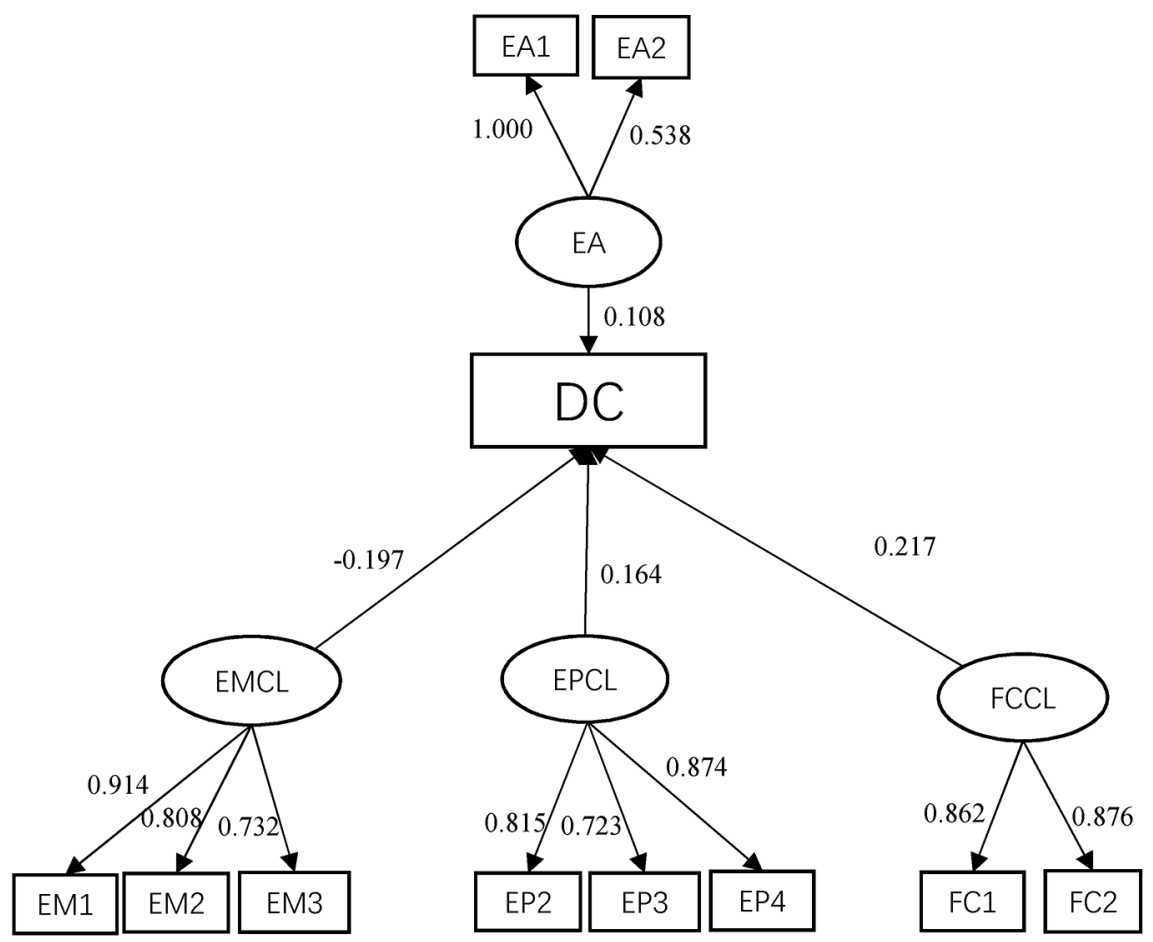

Figure 3. The relationships of environmental awareness, consumption values and green clothes purchase intention.

The overall social value was asked to see if consumers think by making a green purchase on clothes they would feel better compare to others in general, apparently, in our case, it is not reliable for several possible reasons. In market, there is a very limited collection of environmental friendly clothes. There are some brands which offer pure cotton or cashmere but the intention of the selling point to consumers is not environmental friendly but comfortable feeling to wear on body. This may be going to change in near future. For example, $\mathrm{H} \& \mathrm{M}$ just introduced a new collection called H\&M Conscious Exclusive, launched in the market globally on April 7th, 2016. The collection uses recycled fabrics and materials to make clothes and accessories. This collection intentionally was a way to tell consumers that fast fashion industry is not as known as un-environmental friendly as we know today (Massey, 2007). Perceived consumer effectiveness variable was stated as whether consumers think there should be some enforcements for environmental friendly purpose, and the reason for it not reliable to 
clothes is that the bound between environment and clothes industry is relatively low. As we mentioned, there is not a big market needs for such products, and due to the certain functionalities (i.e. waterproof) it is required for those material to be not $100 \%$ natural. Therefore, it is not a good variable to test out the correlation to green purchase decisions, the same reasons applied to indicator EP1 and FC3, for its unpopularity on market demand and unavailable products. The same findings after bootstrap and the explanation for both object clothes and lipsticks that emotion value does not have a positive relationship with green consumption decision.

In addition, the model fit test was conducted respectively in Chinese student sample and international student sample. The results indicated that the model got from international students were very close to what we had for overall impact of our data pool, but the dimensions of environmental awareness and social value had no relationship with green makeup purchase intention in Chinese student sample. Therefore, we conclude that Chinese participants are less likely to be influenced by environmental awareness variables overall, regardless of their idea or knowledge of environment they would still make their decision on makeup purchase by their consumptions values regardless of their decision impact on other surroundings. Previous studies pointed out there is a significant influence of collectivist orientation on Chinese consumers to search for green product and on their actual behavior on green consumption (Chan, 2001; Chan \& Lau, 2002). The current result in Chinese sample might be that because consumers are not familiar with the ingredients and the environmental influences of makeup products for Chinese and the different environmental policies of different countries. Even though China had its long connection with makeup products since $3000 \mathrm{BC}$ and being one of the largest manufacturers, not many females we see in public wear makeup today, especially on college campuses. Environmental policies play a huge role in the market but different countries in the world would have different regulation and limitation for environment. These different standards may cause different actions in the countries of the market. Chinese act more favor on the norm rather than act toward individual interests (Chan \& Lau, 2002). Therefore, the promotion of green cosmetics consumption in China is necessary and have great implication in green marketing.

\section{Conclusion}

Environmental attitude and perceived consumer effectiveness in environmental awareness, and epistemic and functional consumption values had a positive relationship with green makeup purchase intention, but social value in consumption values had a negative relationship with green makeup purchase intention. The model got from international students was very close to what got from the whole data pool, but the dimensions of environmental awareness and social value had no relationship with makeup purchase intention in Chinese student sample. Findings provide implications for promoting green marketing in cosmetics market, especially in Chinese one. For example, the promotion of green makeup 
products in China should start at the promotion of consumption value, especially epistemic and functional value, such as provide a new experience and quality via green makeup products. Then governments could provide more education about the difference between truly natural and natural inspired of makeup, and the influence on the surroundings and the development of society to improve the effects of environmental awareness and social values on green makeup product purchase intention.

Future research should extend the participants, including non-student group and different income groups, and should repeat the study via lab experiment. Given the noted limitations of this study, additional research is needed prior to adopting these results which should be interpreted with caution.

\section{References}

Afroz, R., Masud, M. M., Akhtar, R., Islam, M. A., \& Duasa, J. B. (2015). Consumer Purchase Intention towards Environmentally Friendly Vehicles: An Empirical Investigation in Kuala Lumpur, Malaysia. Environmental Science and Pollution Research, 22, 16153-16163. https://doi.org/10.1007/s11356-015-4841-8

Al-Saleh, I., \& Al-Enazi, S. (2011). Trace Metals in Lipsticks. Toxicological \& Environmental Chemistry, 93, 1149-1165. https://doi.org/10.1080/02772248.2011.582040

Angelovska, J., Sotiroska, S. B., \& Angelovska, N. (2012). The Impact of Environmental Concern and Awareness on Consumer Behaviour. Journal of International Environmental Application and Science, 7, 406.

Bearden, W. O., \& Etzel, M. J. (1982). Reference Group Influence on Product and Brand Purchase Decisions. Journal of Consumer Research, 9, 183-194. https://doi.org/10.1086/208911

Chan, R. Y. (2001). Determinants of Chinese Consumers' Green Purchase Behavior. Psychology \& Marketing, 18, 389-413. https://doi.org/10.1002/mar.1013

Chan, R. Y., \& Lau, L. B. (2002). Explaining Green Purchasing Behavior: A Cross-Cultural Study on American and Chinese Consumers. Journal of International Consumer Marketing, 14, 9-40. https://doi.org/10.1300/J046v14n02_02

Cheah, I., \& Phau, I. (2011). Attitudes towards Environmentally Friendly Products: The Influence of Ecoliteracy, Interpersonal Influence and Value Orientation. Marketing Intelligence \& Planning, 29, 452-472. https://doi.org/10.1108/02634501111153674

Fornell, C., \& Larcker, D. F. (1981). Structural Equation Models with Unobservable Variables and Measurement Error: Algebra and Statistics. Journal of Marketing Research, 382-388. https://doi.org/10.2307/3150980

Garicano, L., Palacios-Huerta, I., \& Prendergast, C. (2005). Favoritism under Social Pressure. Review of Economics and Statistics, 87, 208-216. https://doi.org/10.1162/0034653053970267

Hellier, P. K., Geursen, G. M., Carr, R. A., \& Rickard, J. A. (2003). Customer Repurchase Intention: A General Structural Equation Model. European Journal of Marketing, 37, 1762-1800. https://doi.org/10.1108/03090560310495456

Henion, K. E. (1976). Ecological Marketing. Grid.

Kim, Y., \& Choi, S. M. (2005). Antecedents of Green Purchase Behavior: An Examination of Collectivism, Environmental Concern, and PCE. ACR North American Advances.

Kinnear, T. C., Taylor, J. R., \& Ahmed, S. A. (1974). Ecologically Concerned Consumers: Who Are They? The Journal of Marketing, 20-24. https://doi.org/10.2307/1250192 
Lepisto, L. R. (1974). An Empirical Study of the Effect of Environmental Product Attributes, Convenience, and Price on Product Preference and Socially Responsible Consumer Behavior. Unpublished Doctoral Dissertation. Pennsylvania State University.

Martinho, G., Pires, A., Portela, G., \& Fonseca, M. (2015). Factors Affecting Consumers' Choices Concerning Sustainable Packaging during Product Purchase and Recycling. Resources, Conservation and Recycling, 103, 58-68. https://doi.org/10.1016/j.resconrec.2015.07.012

Massey, M. (2007). What Not to Wear. The World Today, 63, 14-16.

Montano, D. E., \& Kasprzyk, D. (2015). Theory of Reasoned Action, Theory of Planned Behavior, and the Integrated Behavioral Model. In K. Glanz, B. K. Rimer, \& K. Viswanath (Eds.), Health Behavior: Theory, Research, and Practice (5th ed., Chapter 6, pp. 95-124). San Francisco, CA: Jossey-Bass.

Numally, J. C. (1978). Psychometric Theory. New York, NY: McGraw-Hill.

Philippe, M., Didillon, B., \& Gilbert, L. (2012). Industrial Commitment to Green and Sustainable Chemistry: Using Renewable Materials \& Developing Eco-Friendly Processes and Ingredients in Cosmetics. Green Chemistry, 14, 952-956.

https://doi.org/10.1039/c2gc16341a

Roberts, J. A., \& Bacon, D. R. (1997). Exploring the Subtle Relationships between Environmental Concern and Ecologically Conscious Consumer Behavior. Journal of Business Research, 40, 79-89. https://doi.org/10.1016/S0148-2963(96)00280-9

Salovey, P., \& Grewal, D. (2005). The Science of Emotional Intelligence. Current Directions in Psychological Science, 14, 281-285. https://doi.org/10.1111/j.0963-7214.2005.00381.x

Samdahl, D. M., \& Robertson, R. (1989). Social Determinants of Environmental Concern: Specification and Test of the Model. Environment and Behavior, 21, 57-81. https://doi.org/10.1177/0013916589211004

Sheth, J. N., Newman, B. I., \& Gross, B. L. (1991). Why We Buy What We Buy: A Theory of Consumption Values. Journal of Business Research, 22, 159-170. https://doi.org/10.1016/0148-2963(91)90050-8

Tsai, J. L., Chim, L., \& Sims, T. (2015). Consumer Behavior, Culture, and Emotion. In S. Ng, \& A. Y. Lee (Eds.), Handbook of Culture and Consumer Behavior (pp. 68-98). Oxford: Oxford University Press.

Van Liere, K. D., \& Dunlap, R. E. (1981). Environmental Concern: Does It Make a Difference How It's Measured? Environment and Behavior, 13, 651-676. https://doi.org/10.1177/0013916581136001

Vining, J., \& Ebreo, A. (1990). What Makes a Recycler? A Comparison of Recyclers and Nonrecyclers. Environment and Behavior, 22, 55-73. https://doi.org/10.1177/0013916590221003

Werts, C. E., Linn, R. L., \& Jöreskog, K. G. (1974). Intraclass Reliability Estimates: Testing Structural Assumptions. Educational and Psychological Measurement, 34, 25-33. https://doi.org/10.1177/001316447403400104 


\section{Appendix}

\section{Survey Questionnaire \\ Part I. General Info}

Age:

If you are not a female student, please leave this widow.

If you are not a university student, please leave this window.

Your Educational Level: Bachelor; Master; Doctor

What year are you in University: Freshman; Sophomore; Junior; Senior; $1^{\text {st }} \mathrm{yr}$ Master; $2^{\text {nd }}$ yr Master; last yr Master; $1^{\text {st }}$ yr PhD; $2^{\text {nd }}$ yr PhD; last yr PhD; None of the above

Your Nationality: Chinese; I am not Chinese

If you are not Chinese, please specify your ethnical background: Caucasian; African; Asian; Other

Average total monthly income (e.g. including scholarship, job, awards, allowance etc.): Less than 5000; more than 5000

\section{Part II. Environmental Awareness}

$1=100 \%$ disagreed $\mathbf{2}=80 \%$ disagreed $\mathbf{3}=60 \%$ disagreed $\mathbf{4}=50 \%$ agreed, $50 \%$ disagreed $\mathbf{5}=60 \%$ agreed $\mathbf{6}=80 \%$ agreed $\mathbf{7}=100 \%$ agreed.

$\begin{array}{lllllll}1 & 2 & 3 & 4 & 5 & 6 & 7\end{array}$

When I buy products, I try to consider how my use of them will affect the environment and other consumers.

Each consumer's behavior can have a positive effect on society by purchasing products sold by socially responsible companies.

I can protect the environment by buying products that are friendly to the environment.

Since one person cannot have any effect upon any natural resource problem, it does not make any difference of what I do.

When humans interfere with nature, it often produces disastrous consequences.

Mankind is severely abusing the environment.

The balance of nature is very delicate and easily upset.

To maintain a healthy economy, we will have to develop a steady-state economy where industrial growth is controlled.

Agricultural films and plastic wrap both are white pollutants.

Coal is a renewable resource.

Because fertilizer can promote the production of crops, the more fertilizer the better.

Greenhouse gases are mainly sulfur dioxide.

Commercial advertising should be forced to mention the ecological disadvantages of products. 


\section{Continued}

Manufacturers should be forced to use recycled materials in their manufacturing and processing operations.

I am supportive of the system of "pay for using plastic bag". (i.e. at the supermarket for every plastic bag, you need to pay extra)

I would pay one yuan more each month to support greater control of environment.

\section{Part III. Consumption Values}

Please rate makeup and clothes respectively under given statements

$1=100 \%$ disagreed $2=80 \%$ disagreed $3=60 \%$ disagreed $4=50 \%$ agreed, $50 \%$ disagreed $\mathbf{5}=60 \%$ agreed $\mathbf{6}=80 \%$ agreed $7=100 \%$ agreed

The "makeup" that mentions in the survey please refer it as lipsticks. Green $=$ Eco-friendly (could mean natural/no animal testing/no chemical ingredient/recyclable etc.

The clothes that mentions in the survey please refer it as tops. Green = Eco-friendly (could mean $100 \%$ cotton or silk/ no fur/ recyclable wrapping etc.

\begin{tabular}{l} 
Buying the following green products instead of conventional \\
products would make me feel like making a good personal \\
contribution to something better. \\
Buying the following green products would make me feel like \\
the morally right thing. \\
Buying the following green products would make me feel like \\
I am a better person. \\
Buying the following green products would make me feel like \\
I made a wise decision. \\
Buying the following green products would make me feel like \\
I have higher level of consciousness than others. \\
Buying the following green products would show my \\
sympathy and my caring. \\
Buying the following green products would make a good \\
impression on other people. \\
Buying the following green products would show my income \\
level. \\
I would like to search for the new and different of the \\
following green products. \\
I would acquire a great deal of information about what are \\
the differences that make green products so special. \\
Buying green products would help me satisfy my curiosity. \\
Buying the following green products would bring me a new \\
experience. \\
The following green products can fulfill all the needs that I \\
look for in a product (functionality). \\
I think the following green products have consistent quality. \\
I think the following green products are resonabily priced. \\
I think the following green products offer good value for \\
their price. \\
\hline
\end{tabular}




\section{Part IV. External Variables}

Animal Testing/Chemical Ingredient/Waste

Please rate the following given statements

$1=100 \%$ disagreed $2=80 \%$ disagreed $3=60 \%$ disagreed $4=50 \%$ agreed, $50 \%$ disagreed $\mathbf{5}=60 \%$ agreed $\mathbf{6}=80 \%$ agreed $\mathbf{7}=100 \%$ agreed

\begin{tabular}{lllllllll}
\hline & 1 & 2 & 3 & 4 & 5 & 6 & 7 \\
\hline Animal tests are needed to ensure that products are not & & & & & \\
harmful to human \\
I would still purchase products which are being tested \\
on animals \\
I would use expired makeup for other use. (e.g. mix \\
expired lipstick with clear nail polish to make colored \\
polish) \\
I would buy the prettier looking product even though \\
products have the exactly same contents. \\
I read the ingredients chart before I make a purchase \\
All the makeup products contain chemical ingredients, \\
so it is pointless to care about it so much
\end{tabular}

Other parts

$\begin{array}{lllllll}1 & 2 & 3 & 4 & 5 & 6 & 7\end{array}$

The well-known brands are best for me.

Upscale specialty and department stores offer me the best products.

I prefer to buy foreign brands than local brands.

As long as the brand is famous, the product does not have to be the best to satisfy me.

I prefer to buy the best-selling products.

I keep up myself with the newest fashion trend.

I always own the newest products.

I do not care what is selling in the market, I remain my personal style. (please also select "agreed" if you are the fashion follower)

I would feel ashamed if I do not have something that everyone else has.

I buy what my close friends buy.

If I know everyone has a particular product then I must have it as well.

Even though I may not like it but if other people tell me I

should have this product, I will still buy it.

I buy the products that my favorite movie stars and pop singers are using.

I buy the products that everyone talks about.

I buy the products I usually see on the media.

I do not believe what is shown on advertisement.

Better brand means better quality.

Higher price means better quality.

Quality is the only concern while I am choosing a product.

If quality is same, I would prefer to choose the cheaper brand. 


\section{Part V. Purchase Intention}

$\begin{array}{lllllll}1 & 2 & 3 & 4 & 5 & 6 & 7\end{array}$

I will buy green makeup to guarantee my health.

I would like to pay more for green makeup for high quality life.

I recommend green makeup that I consumed to my relatives and friends.

I would like to buy green makeup to reduce environmental damage.

I would purchase a less packaging product.

While purchasing the goods, I will consider whether it is environmental-friendly.

I am willing to pay more money to buy environment-friendly products.

\section{Part VI.}

In general, how do you make purchase of makeup product? (choose ANY answer that applies):

- Online

- In department store (e.g. Saks fifth ave)

- Open-shelf market (e.g. Sephora)

- Some stores

- I do not buy them

- Others (Please specify)

If there is only one makeup item that you can buy, which of the following would you choose?

\section{- $\mathrm{BB} / \mathrm{CC}$ cream}

- Mascara/Lash Enhancers

- Eye Shadow

- Eyeliner

- Eyebrow Pencil

- Concealer for EYES

- Lipstick

- Gloss/Balms

- Lip Pencil

- Foundation/Primer

- Tinted Moisturizer/Concealer for FACE

- Blush

- Bronzer/Luminizer

How much do you want to have a lipstick? (Rate from number 1 - 5)

How do you learn about certain makeup product? (choose ANY answer that applies)

- From movies

- From magazines 
- From sales

- From friends or family

- From internet

- From somewhere, based on my own choice

- Others (please specify)

On average, how long do u shop online per time?

- less than half hour

- half to one hour

- one to one and half hours

- one and half to two hours

- more than two hours

- I do not shop online

How much more would you like to spend on eco-friendly makeup products (i.e. lipsticks)?

- 0 RMB

- $10-30 \mathrm{RMB}$

- $31-60 \mathrm{RMB}$

- $61-100 \mathrm{RMB}$

- $100-150 \mathrm{RMB}$

- $151-200 \mathrm{RMB}$

- $200+\mathrm{RMB}$

What do you think when we talk about eco-friendly/green makeup? (choose ANY answer that applies)

- no animal testing

- no chemical ingredients or all natural

- recyclable (i.e. container)

- Others (please specify)

Please tell us if you would make a green consumption decision. 